\title{
Astrocytoma of the retina
}

\author{
Report of a case
}

\author{
JOSE JORDANO, HUGO GALERA, MARIANO TORO, \\ AND BUENAVENTURA CARRERAS
}

From the Departments of Ophthalmology and Pathology, University of Granada School of Medicine, Spain

Astrocytomas are rarely found in the eye. In the literature which we have reviewed, we have found only five well-documented cases (McLean, 1937; Marks, Willis, and Anderson, I939; Boles, Naugle, and Samson, I958; Foos, Straatsma, and Allen, I965; Cleasby, Fung, and Shekter, 1967) which were not associated with tuberous sclerosis or with neurofibromatosis, and were not formed by an intraocular extension of an astrocytoma of the optic nerve. There are four additional reports of intraocular gliomas not associated with phakomatosis: one of these was considered to be derived from Müller's cells (Orton and Willis, I944); two others were believed to be oligodendrogliomas (Boniuk and Bishop, I969; Huggert and Hultquist, 1947); the case described as an astrocytoma by Dejean (1934) also seems to correspond to an oligodendroglioma, which agrees with the opinion of Russell and Rubinstein (197I).

A retinal astrocytoma may present a clinical picture indistinguishable from that of a retinoblastoma. The rarity of this tumour and the difficulties of differential diagnosis are demonstrated by the fact that, in a survey of 500 children with suspected retinoblastoma (Howard and Ellsworth, I965a), not one case of astrocytoma was described. The present case is recorded in order to illustrate some of the clinical and pathological problems of diagnosis, and to add to the few existing reports of this condition.

\section{Case report}

A girl aged 9 years was seen for the first time on November 29, 1972. She had noticed poor central vision in the right eye with no pain or obvious external change 8 months previously, and at that time another ophthalmologist had recorded a visual acuity of counting fingers at $0.5 \mathrm{~m}$., a central scotoma with external reduction of the visual field, and a gross "tuberculoma" located at the posterior pole of the right eye. Systemic examination and laboratory tests were negative, except for the Mantoux test $\mathrm{I} / \mathrm{I00}, 000(++)$. She had been treated with tuberculostatic drugs and steroids, but the visual acuity continued to deteriorate, and her parents decided to interrupt the therapy and did not seek further medical advice.

She came to us because of acute onset of uncontrollable pain and congestion of the right eye. 


\section{Examination}

The right eye showed amaurosis, intense ciliary injection, corneal oedema, hyphaema, gross rubeosis iridis, posterior synechiae, and leucocoria. Applanation pressure was $50 \mathrm{~mm}$.Hg. The left eye was normal. The preoperative diagnosis was haemorrhagic glaucoma secondary to possible intraocular tumour.

\section{Surgery}

On December 3, the right eye was enucleated and a gold ball implanted. Routine preoperative analyses and general examination showed nothing abnormal, and the postoperative course was uncomplicated. When the pathological report was available, an extensive search for evidence of hamartoma was undertaken. This included neurological, dermatological, psychiatric, cardiovascular, renal, and radiological studies; all these, as well as the family history and examination of the parents, were negative.

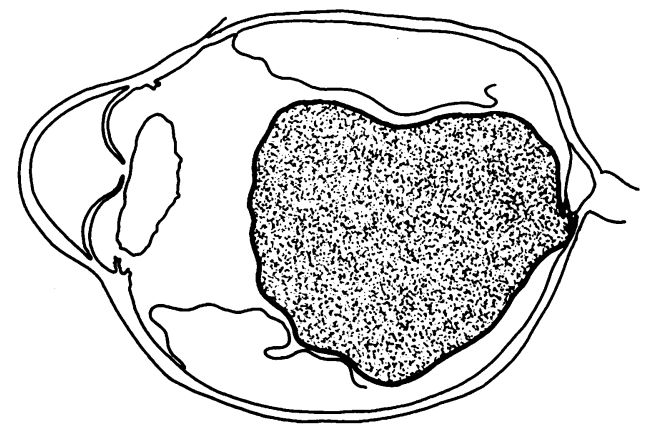

FIG. I Section through enucleated eye

\section{Pathological report}

The eye measured $2 \mathrm{~cm}$. in diameter and the cornea was prominent. The choroid and ciliary body were congested. At the optic disc, there was a greyish nodular neoformation $1 \cdot 2 \mathrm{~cm}$. in diameter. This tumour had invaded the vitreous, causing detachment of the retina with a subretinal deposit of watery fluid (Fig. I). Microscopic observation revealed a retinal tumour which was inserted in the optic disc (Fig. 2A) and was composed principally of polygonal astrocytes with eosinophilic cytoplasm and a rounded or oval nucleus (Fig. $2 \mathrm{~B}$ ). The cytoplasmic expansions interlaced to form a complex network or perivascular process. With Rio Hortega's silver carbonate technique, it was observed that the astrocytes seemed to be of the protoplasmic (Fig. $2 \mathrm{C}$ ) rather than the fibrous type, and that their extensions were few and short. There were no mitoses and morphological irregularities were not prominent. Small calcium deposits and extensive areas of necrosis were present. Prominent vascular proliferation was also observed, principally near the point of insertion. Some of these vessels were dilated but, in general, an increase in the number of cellular elements of the vascular wall was noted. The tumour seemed to be purely retinal. It was attached to the disc in the front of the lamina cribosa and did not infiltrate the optic nerve. The internal limiting membrane was intact. Oedema and disorganization of the nuclear layers as well as a slight diffuse gliosis were observed in the greater part of the remaining retina. At the root of the iris, there was congestion, connective tissue, and vascular proliferation forming peripheral anterior synechiae.

\section{Diagnosis}

Astrocytoma of the retina and optic disc.

\section{Discussion}

Since the retina is, embryologically, an extension of the primary cerebral vesicle, it might be expected to bear neoplasms similar to those formed in the brain proper. To some extent 


557

FIG. 2 (A) Low-power view of posterior retinal tumour. Note mass inserted in optic disc without extension into optic nerve. $\times 20$. (B) High-power view of cellular detail. The gliomatous proliferation is composed of polygonalshaped astrocytes with eosinophilic cytoplasm. $\times$ 400. (C) High-power view of a section stained by Rio Hortega's silver carbonate technique. Most of the neoplastic cells are protoplasmic astrocytes. $\times 400$ 
this is true, but the retina and other derivatives of the optic cup are so highly specialized in their later development that their neoplastic manifestations have, in their turn, peculiarities that demand separate consideration (Russell and Rubinstein, 1971). One of these peculiarities is the rarity of the astrocytoma in this localization, to which we have referred above. However, such tumours are not so extremely rare in patients with tuberous sclerosis or with neurofibromatosis. In the case reported here, no evidence of phakomatosis was discovered.

Howard and Ellsworth ( $1965 \mathrm{~b}$ ), describing the criteria for differential diagnosis of retinoblastoma, mention no specific features which would assist the clinical diagnosis of these cases of retinal astrocytoma. In spite of this, evidence of tuberous sclerosis or neurofibromatosis in a child with fundus tumour. would support the diagnosis of true glioma rather than retinoblastoma. In this sense, the presence of clumped tumour cells in the vitreous or anterior chamber would strongly suggest a diagnosis of retinoblastoma, since astrocytomas do not break through the internal limiting membrane (Hogan and Zimmerman, I962).

Retinal astrocytomas of all types are still generally regarded as hamartomatous even if there is no association with neurofibromatosis or tuberous sclerosis (Hogan and Zimmerman, 1962). Whether such tumours should be considered as hamartomas in the absence of other underlying or associated developmental anomalies seems doubtful (Foos and others, I965).

From the histological point of view, certain aspects should be emphasized in the present case: the tumoural appearance of the proliferative mass within the eye, the close similarity of its cellular components to those of the astrocytomas which occur elsewhere in the central nervous system, the absence of extension into the optic nerve, and the predominance of the protoplasmic form of the astrocytes. In relation to this last point the majority of authors (McLean, 1937; Marks and others, I939; Boles and others, I958; Foos and others, I965) have noted the predominance of the fibrous form of the astrocytes in such tumours. We were unable to ascertain where this tumour first originated, but a previous ophthalmological report suggests that the mass was first located at the posterior pole and then encroached upon the disc. The clinical appearance of haemorrhagic glaucoma observed in this patient may be seen in cases of advanced retinoblastoma (Walton and Grant, I968; Bedford, Bedotto, and Macfaul, I97I) and has also been described in association with a glioma of the intraorbital portion of the optic nerve (Hovland and Ellis, 1966). Apparently, vascular proliferation of the iris may follow the circulatory disturbance of the retinal system caused by a tumoural growth or reactive gliosis.

\section{Summary}

A case is described of astrocytoma of the retina, unassociated with tuberous sclerosis or neurofibromatosis. It was first diagnosed clinically as haemorrhagic glaucoma secondary to possible intraocular tumour. Special problems relating to the clinical diagnosis and the pathological appearance are discussed.

\section{References}

Bedford, м. A., Bedotto, C., and maGfaul, P. A. (197I) Brit. F. Ophthal., 55, 19 Boles, W. M., Naugle, T. c., and samson, c. L. M. (1958) A.M.A. Arch. Ophthal., 59, 229 BONIUK, M., and BISHOP, D. (1969) Surv. Ophthal., 13, 284 
Cleasby, G. W., fung, w. E., and Shekter, w. B. (1967) Amer. F. Ophthal., 64, 633 DEJEAN, G. (1934) Arch. Ołhtal., 51, 257

Foos, R. Y., StraAtsma, B. R., and Allen, R. A. (1965) Arch. Ophthal. (Chicago), 74, 319 hogan, M. J., and zimmerman, L. E. (r 962) "Ophthalmic Pathology", p. 525. Saunders, Philadelphia HOVland, K. R., and Ellis, P. P. (1966) Arch. Ophthal. (Chicago), 75, 806

hoWARD, G. м., and ellsworth, R. м. (1965a) Amer. F. Ophthal., 6o, 6ro (I965) Ibid., 6o, 618

HUGGERT, A., and HULTQUIST, G. T. (1947) Ophthalmologica (Basel), 113, 193

MARKs, E. O., Willis, R. A., and ANDERson, J. R. (1939) Trans. ophthal. Soc. Aust., I, 46

mGlean, J. M. (1937) Arch. Ophthal. (Chicago), 18, 255

ORTON, R. H., and willis, R. A. (1944) F. Path. Bact., 56, 255

RUSSEll, D. S., and RUBinstein, L. J. (I97I) "Pathology of Tumours of the Nervous System", p. 227.

Arnold, London

walton, D. s., and GRANT, w. M. (1968) Amer. F. Ophthal., 65, 598 